\title{
O Desaparecimento de Enrique Sayagués Laso (1911-1965) Perda para a Ciência do Direito Administrativo.
}

\author{
Leon Cortiñas Pelaez \\ Assistente de Direito Administrativo na Facul- \\ dade de Direito do Montevidéu.
}

A ciência juridica podia jactar-se de ter, há dez anos, na Faculdade de Direito de Montevidéu, três figuras de envergadura universal: as construções do diretor EDUardo J. Couture ${ }^{1}$ em direito processual, as de Quintín Alfonsín ${ }^{2}$ em direito privado internacional, e a de Enrique Sayagués LAso $^{3}$ em direito administrativo, sobrepujavam amplamente as fronteiras da República Oriental da América latina e colocavam seus autores entre os espíritos mais brilhantes e mais sólidos do mundo jurídico contemporâneo. Couture, desaparecido aos 52 anos, poucos dias depois da reeleição que ia permitir-lhe completar suas realizações como diretor no mandato mais nobremente

1. (1904-1956), autor de Fundamentos del Derecho Procesal Civil, ed. Depalma, Buenos Aires, 1942 (3. ${ }^{a}$ ed. póstuma, 1958) ; Introduction à l'Etude de la Procédure Civile, ed. Sirey, Paris, 1949; Estudios de Derecho Procesal Civil (3 vols.), ed. Depalma, Buenos Aires, 1948-51; Vocabulario del Derecho Procesal Civil, Montevideo, ed. póstuma por Jorge Peirano Facio e José Sánchez Fontáns, "Biblioteca de publicaciones oficiales de la Facultad de Derecho y Ciencias Sociales", 1960.

2. (1910-1961), autor de Teoría del Derecho Privado Internacional, 1955 e de Sistema del Derecho Privado Internacional (I: Derecho civil internacional), 1961, ambos editados pela Faculdade de Direito e Ciências Sociais de Montevideo.

3. Acabava de publicar em 1953, a primeira edição de seu Tratado de Derecho Administrativo, ed. do autor, Montevideo. 
ambicioso e criador que Montevidéu conheceu; Alfonsín, vítima de um acidente de aviação quando todo um continente via já em sua lógica irrefutável a carta decisiva dos países da lex domicilii. Desta tríada excepcional sobreviveu sòmente SAYAgús LASo, o mais jovem, cuja publicação em francês da parte geral do seu Tratado confirmava a repercussão intercontinental de seu ensino. Desaparece, tràgicamente assassinado, na plenitude de sua produção intelectual, aos 54 anos.

Numerosos testemunhos demonstram quão doloroso foi seu desaparecimento. O diretor José GuILlermo ANDUEzA (Caracas) representando tôdas as Faculdades de Direito latino-americanas, cuja IV Conferência - em grande parte obra do dinamismo criador de SAyagués LAso teve lugar em Montevidéu, poucos dias depois; a palavra do professor Marcel Waline na Secção de Direito Público da Faculdade de Direito e Ciências Econômicas de Paris; o seu diretor Georges Vedel, participando à totalidade do corpo docente da mesma; o Colégio dos Advogados do Uruguai organizando, sob a presidência do professor ARmando MaLeT, uma semana de estudos de direito administrativo à memória do grande publicista ${ }^{4}$; as Faculdades de Direito de La Plata (Argentina) e Caracas (Venezuela) organizando Jornadas de Estudo em sua memória; o Conselho da Universidade do Chile criando uma bôlsa que levará seu nome; desde os primeiros dias, todos destacam sua magnífica carreira e sublinham a perda que sua morte

4. Com a participação de especialistas das Faculdades de Direito e Ciências Sociais, e de Ciências Econômicas e Administração, esta semana dedicada especialmente ao estudo das recentes reformas do direito administrativo uruguaio, se ocupou dos seguintes temas: 1) Garantías en el Procedimiento Administrativo; 2) Organos y Actos de Coordinación; 3) La notificación del Administrado; 4) Competencia del Tribunal y su Potestad de Suspender la Ejecución de los Actos Administrativos; 5) El Plazo para Ejercitar la Acción de Nulidad; 6) La Representación del Estado ante el Tribunal de lo Cortencioso Administrativo; 7) La Prueba en el Contencioso Administrativo; 8) Expropriación; 9) Control de la Actividad Bancaria. 
significa para a Ciência e para a Universidade. A projeção mundial de seu desaparecimento será fundamentalmente ilustrada em 1967 e 1968 pela publicação de uma obra coletiva, em três volumes, com a contribuição de aproximadamente 130 autores, do mundo inteiro, (dos quais mais de 100 estrangeiros), obra que of erecerá sob o título Perspectivas del Derecho Público en la Segunda Mitad del Siglo XX, uma documentação de primeira ordem sôbre a irradiação planetária do pensamento de EnRIQue SAYagués LAso nas diferentes perspectivas do direito público ${ }^{5}$.

Desaparece em sua plenitude intelectual, no momento mesmo em que, terminada a supervisão da tradução francesa do Tratado, compreendendo os dois volumes da teoria geral ${ }^{6}$, acabava de determinar o plano detalhado dos dois volumes finais, consagrados à parte especial e destinados a aparecer sòmente em espanhol ${ }^{7}$. A sua obra teria sido assim coroada; porém tal qual subsiste, ela se basta a si mesma. Seu autor havia chegado a uma concepção da ciência e da técnica do direito administrativo que êle mesmo considerava como acabada. Este ponto de vista se expressa, não só pela forte síntese representada pelo Tratado e pelas numerosas obras que o precederam mas

5. A obra será editada pela Revista de Derecho, Jurisprudencia y Administración (Montevidéo), com prefácios de MARCEL WALINE (Paris) e Julio A. Pratt.

6. Traité de droit administratif publicado sob o auspício do "Centro Français de droit comparé", prefácio de HenRI PUGET, tradução de Simone AICARDI, 2 vls., Paris, 1964, (esta data corresponde de fato ao vol. I, o vol. II tendo sido impresso em 1965 e a distribuição não tendo começado senão em 1966 pela "Librairie générale de droit et de jurisprudence" de Paris.

7. Para esta parte especial existem 4 volumes, Derecho administrativo 2. a edição do "Centro Estudiantes de Derecho", Montevideo, 1957/58, versão gravada e edição mimeografada de seus cursos. Porém um Curso não é um Tratado, repetia SAYAGuÉs LASo indicando com isso o desnível existente entre os ditos volumes e o que êle se exigia para sua obra: não autorizou sua publicação senão como uma contribuição para diminuir as dificuldades dos estudantes e com a esperança de substituí-los ràpidamente pelos volumes 3 e 4 do Tratado. 
também pela quantidade de comentários, consultas e artigos disseminados em publicações "orientais" e estrangeiras.

Temos procurado estabelecer uma nomenclatura completa das mesmas (v. Anexo); porém logo nos pareceu que deviamos à sua memória fazer preceder esta bibliografia de uma análise sumária de sua vida e obra. Agradecemos desta maneira a esta Revista por nos haver cedido algumas de suas páginas para que pudéssemos homenagear a quem foi para nós, na República Oriental e na Europa, um mestre e um amigo.

A concepção pedagógica e científica de sua obra, o Tratado de Derecho Administrativo, é a projeção natural de um caráter forjado por uma vida dedicada à ciência jurídica e ao ensino do direito, ao fôro e à compreensão internacional estimulada pelo direito comparado, vida que se havia exteriorizado em numerosas publicaçôes antes do ano decisivo de 1953.

I.

Com efeito, antes da publicação do seu Tratado, forja em seu país não só uma personalidade mas sim um caráter, e começa a se desenvolver no plano internacional.

De seu pai, professor de direito administrativo, e de sua mãe, cujas telas foram distinguidas em exposições internacionais, o futuro grande jurista recebe a fôrça de sua vocação e a fina sensibilidade de seu espírito.

Realiza estudos particularmente brilhantes, doutorando-se em direito em 1934, para começar em 1935 uma tríplice carreira: administrativa, forense e docente que ja durar 30 anos.

Primeiramente secretário e logo sub-gerente da "Administração Nacional de Combustíveis, Alcool e Cimento" (A.N.C.A.P.) adquire nela o conhecimento direto da administração pública e das exigências jurídicas naturais a um 
serviço estatal eficaz porém, ao mesmo tempo, responsável perante os administrados.

O exercício intenso da advocacia o introduz, na luta contra as manobras dos particulares, para travar a boa marcha da administração, e na defesa dos particulares contra os abusos do poder público.

Assistente de direito administrativo após seu doutoramento, é designado professor-adjunto, em 1939, com uma tese sob La Licitacion Pública. Mas Montevidéu era então uma pequena cidade universitária, cuja população estudantil só aumentaria consideràvelmente após a segunda guerra mundial. SAYAGUÉs LASO não pôde aproximar-se senão muito lentamente da única cadeira: só a criação de duas novas ("Instituições de direito administrativo" e "Direito administrativo especial") lhe permitem ser primeiramente Encarregado de ambas as cadeiras (1947-48) e Catedrático em 1954, quando já era Professor ad honorem da Universidade do Chile, desde 1950.

Durante esta longa espera de vinte anos, trabalha incansàvelmente em seu Tratado, enquanto se forja como jurista de inquietudes variadas que enriquecem a solidez de sua formação. Se a cátedra está transitòriamente fechada, paciência e tenacidade inquebrantáveis não se acompanham de indiferença, diante de outros horizontes que se abrem ante seus olhos.

Aborda, inicialmente, o direito privado no qual seus conhecimentos de teoria geral do direito lhe permitem triunfar, como uma obra original sôbre a concordata, que estrutura procedimentos ainda não superados para a chamada "concordata de liquidação" e que continua sendo depois de 30 anos a grande obra de consulta na matéria 8 . Porém seu espírito não se limita a uma especialização demasiado estrita, e o conduz a estudos processuais nos quais chega a esgotar o direito positivo relativo às insti-

8. El concordato, obra premiada pela Faculdade no Concurso de obras jurídicas de profissionais de 1934, Montevideo, ed. Peña \& Cia., 1937. 
tuições dos processos civil e penal a cujo estudo se dedica ${ }^{9}$. Mais tarde, um conhecimento exaustivo do direito "oriental" interno, público e privado, lhe permite lançar uma síntese que sistematiza durante cinco anos o conjunto jurídico do país ${ }^{10}$; esta última experiência, única na República Oriental, o conduz naturalmente a ser nomeado primeiro diretor da Revista da Faculdade ${ }^{11}$, que alcança durante os dez anos de sua direção (1950-60) um elevado nível científico, combinando a reunião dos melhores mestres do mundo com uma abertura aos países latino-americanos, sem prejuizo de reservar um papel fundamental aos jovens docentes de Montevidéu.

Porém as fronteiras do país natal começam a ser demasiado estreitas: a cátedra não o leva a esquecer o que Jhe permitiu ver a vida internacional dos advogados e professôres de direito. Trata de abraçar ambas perspectivas.

Membro e várias vêzes vice-presidente do Colégio dos Advogados do Uruguai, passa a ser membro do Comité Executivo, e, após, do Conselho da "Inter-American-Bar Association" em 1947. Nesta qualidade, participa das Conferências continentais de Lima (1947), Detroit (1949), Montevidéu (1951, que organiza como vice-presidente, conjuntamente com Eduardo J. Couture, seu presidente), São Paulo (1954) e Buenos Aires (1957), nestas duas últimas

9. Suspensión condicional de la ejecución de la pena (sôbre as leis de 25 de janeiro de 1916 e de 8 de junho de 1921), Montevideo, ed. Barreiro y Ramos, 1932; e Recurso extraordinário de nulidad notoria, premiado no Concurso anual de trabalhos estudantis de 1932, ed. "Biblioteca de publicaciones oficiales de la Facultad de derecho y ciencias sociales" de Montevideo, 1934.

10. Repertorio jurídico (Indice completo do material legislativo, administrativo, jurisprudencial, doutrinário e bibliográfico, contido em tôdas as revistas ou publicações jurídicas nacionais aparecidas no ano), 4 vols. $(1943,1944,1945,1946,1947)$ Montevideo, ed. da Revista de Derecho Público y Privado.

11. Revista de la Facultad de Derecho y Ciencias Sociales, Montevideo. 
na qualidade de relator. Simultâneamente dá aulas e faz conferências nas Universidades respectivas, nas quais seu talento de professor desperta o respeito e admiração de colegas e estudantes.

Estes contactos internacionais de advogados o sensibilizam para o problema da proteção internacional dos Direitos Humanos, em meio de uma América Latina infestada de ditaduras indiferentes à entrada em vigência da Declaração Universal de 1948. Ilumina, não sua proclamação mais ou menos vazia, mas a questão decisiva de fazê-los eficazes mediante um contrôle jurisdicional internacional adequado. Em 1952, em Havana e Lima, países submetidos então a sangrentas ditaduras, não vacila em ir defender, convidado respectivamente pela U.N.E.S.G.o. e o. Colégio dos Advogados do Peru, a tese "oriental" da fôrça obrigatória da Declaração e da urgente necessidade de adotar a proposta "oriental" de um Procurador ou espécie de "ombudsmann" internacional 12. Sustenta ali que tôdas as regras da Carta de São Francisco são normas jurídicas e por isso obrigatórias; que sua falta de desenvolvimento normativo ou de garantias permite promover a responsabilidade dos organismos internacionais obrigados à assegurar sua execução. Desenvolve assim a escala internacional o princípio da responsabilidade irrestrita dos órgãos públicos, princípio do que seria tenaz defensor em seus cursos e em seu Tratado, continuando assim brilhantemente ${ }^{13}$, uma doutrina inaugurada em direito latino-

12. O curso de Havana foi publicado com o título Los derechos humanos y las medidas de ejecución, Revista de la Facultad de Derecho y Ciencias Sociales, Montevideo, 1953, p. 273-356.

13. Fundamentalmente em seu Tratado, t. I, p. 593 ss., antecedido por sistemáticos estudos jurisprudenciais (Responsabilidad por acto o hecho administrativo en "La revista de derecho, jurisprudencia y administración”, Montevideo, 1950), dotrinários (La responsabilidad por acto o hecho administrativo en "Jurisprudencia argentina", Buenos Aires, 1950, t. II da seç̧ão doutrina, p. 48) e de direito comparado (Responsabilité de l'Etat..., infra, nota 24). 
americano por seu pai Rodolfo Sayagués LASo ${ }^{14}$, em princípios do século, acompanhado por duas das mais eminentes figuras da doutrina francesa de todos os tempos, LÉoN Duguit ${ }^{15}$ e Georges Scelle ${ }^{16}$. Mas seu espírito dotado de rica formação teórica, sabe, sem embargo, ser concreto e realista. Os fracassos sucessivos das comissões da o.N.U., encarregadas do estudo dos projetos em discussão não o desanimam: em lugar de deter-se como jurista romanogermânico típico no conteúdo mais ou menos discutivel dos direitos proclamados, tem uma preocupação de commonlawyer: a de dar-lhes plena vigência ainda que pela adoção de um mínimo denominador comum, mas insistindo tenazmente nas soluções consideradas como as methores. Diz:

“( . . ) continua a insuficiência de meios (. . ) Não obstante, sempre se dá um passo adiante (. .) ${ }^{17}$. Não vejo de nenhuma maneira o problema com critério pessimista. Pelo contrário. O que ocorre é que nesta matéria temos que avançar passo a passo, e os triunfos se conseguem sòmente depois de muitos anos (. ) até mesmo séculos" ${ }^{18}$.

E o realismo do especialista forense ressurge para aconselhar procedimentos complementares de tipo não jurisdicional, susceptiveis de terem soluções mais aceitáveis para o Estado culpável ${ }^{19}$.

14. La responsabilidad del Estado por actos legislativos, Montevideo, "Revista de derecho y ciencias sociales", 1914, t. 'I., p. 514-541.

15. Revue du droit public, Paris, 1913, p. 637-66.

16. A propos de l'établissement du monopole des assurances en Uruguay, "Revue du droit public", Paris, 1913, p. 637; reproducido en "La revista de derecho, jurisprudencia y administración", Montevideo, t. 22, p. 150 .

17. Los derechos humanos y las medidas de ejecución, p. 315 .

18. Ibidem, p. 330 e p. 355.

19. A experiência de 1952 o faz participar mäis tarde de pleno direito da mesa redonda sôbre o projeto de Convenção de direitos humanos, elaborado em Santiago pela IV Reunião do Conselho inter- 
Esta irradiaçâo internacional de seu magistério é acompanhada já nesta época do amadurecimento de uma firme vocação de comparatista. Organizador e relator nas Jornadas Franco-Latinoamericanas de Montevidéu em $1948^{20}$, é com o diretor Eduardo J. Couture a alma das Jornadas de Direito Comparado que a "Association Henri Capitant pour le développement de la culture juridique française" e a Faculdade de Direito e Ciências Sociais de Montevidéu organizam em $1954^{21}$ Acaba de representar a Universidade do Urugı ai no oitavo Congresso internacional de municípios am ricanos (Punta del Este, 1953) e participa seguidamente das Jornadas de Direito Comparado Argentino-Uruguaias ${ }^{22}$, Chileno-Uruguaias ${ }^{23}$ e Santafecino-Uruguaias de Buenos Aires (1956), Montevidéu (1959), Santa Fé (1960), Santiago (1961) e Montevidéu (1961 e 1963). Em 1965 ia orientar um curso conjuntamente com o professor Fernando Garrido Falla, da Faculdade de Direito de Madrid, para um grupo de professôres e graduados da América Central, reunidos em San José

americano de Juristas, cujos debates foram publicados em Simposio sobre el proyecto de Convención de derechos humanos de Santiago de Chile, Montevideo, "Biblioteca de publicaciones oficiales de la Facultad de derecho y ciencias sociales", 1959.

20. Jornadas Franco-Latino-Americanas de Derecho Comparado (Montevideo, 1948), organizadas pela Faculdade de Direito e Ciencias Sociais do Uruguai e a "Société de législation comparée", Montevideo, "Biblioteca de publicaciones oficiales de la Facultad de derecho y ciencias sociales", Montevideo, 1951, p. 1-257.

21. Reproduzidas pela "Revista de la Facultad de Derecho y Ciencias Sociales", Montevideo, 1955, p. 1-574.

22. Jornadas Rioplatenses para la Unificación de la Legislación Argentina y Uruguaya (em homenagem aos Drs. HECTOR LA FAILs e Eduardo J. Couture), Buenos Aires 1956, oportunidade em que fêz um curso na Faculdade de Direito de Buenos Aires.

23. Jornadas de Derecho Comparado Chileno-Uruguayas, organizadas pelas Faculdades de direito de Santiago de Chile e de Montevideo, Montevideo, "Biblioteca de publicaciones oficiales de la Facultad de derecho y ciencias sociales", 1959, reproduzidas pela "Revista de la Facultad de derecho y ciencias sociales", Montevideo, 1959, p. 1-710. 
de Costa Rica; e depois participar no Congresso de Paris do Instituto Internacional de Ciências Administrativas. A morte o impediu.

Porém, o triunfo já o havia consagrado em Paris. Em 1952, pela passagem do $1500^{\circ}$ aniversário do Conselho de Estado da França, Enrique Sayagués Laso teve a honra de ser, com o brasileiro Temístocles Cavalcanti os únicos juristas da América Latina, convidados a colaborar no Livro Jubilar ${ }^{24}$; em 1954, como Couture pouco antes ${ }^{25}$, leciona na Universidade de Paris, primeiramente na Faculdade de Direito sôbre Quelques Observationes à la Théorie Générale de l'Act Administratif, depois na Fundação Nar cional de Ciências Politicas sôbre Les Etablissements Publics Economiques en Uruguay ${ }^{26}$. Membro da "Société de législation comparée de Paris" (desde 1955) e do Conselho diretivo do "Comité France-Amérique" de Montevidéu (desde 1956), se empenha em estimular - particularmente após sua nomeação como Diretor de Instituto de Direito Público da Faculdade de Direito de Montevidéo (1958) os vínculos entre esta e as Faculdades de Direito francesas. Isto e a irradiação intercontinental de seu Tratado, particularmente acentuada pela tradução francesa, the grangeiam a Legião de Honra em janeiro de 1965 e uma proposta unânime da Faculdade de Direito e Ciências Econômicas de Paris para o doutorado "Honoris Causa" em março de 1965.

Esta tríplice carreira de administrador, advogado e docente se completa crescentemente com uma atividade de conselheiro de numerosas instituições públicas e privadas.

24. Conseil D'Etat, Livre Jubilaire Publié pour Conmémorer son Cent Cinquentième Anniversaire (4 nivose an VIII - 24 décembre 1949), Paris, Recueil Sirey, 1952, p. 619-632 com o título "Responsabilité de l'Etat en Raison des Actes Législatifs, reproduzido com o título Responsabilidad por Acto Legislativo na "Revista de jurisprudencia peruana", Lima, 1953, vol. 2, p. 410 ss.

25. Supra, nota (1).

26. Reproduzido na "Revue International des Sciences Administratives", Bruxelles, t. 22, p. 5 ss., 1956. 
Em matéria legislativa, muito especialmente não se deve omitir seu papel fundamental na elaboração da leì orgânica municipal (1956), da lei orgânica da Universidade da República em $1958^{27}$, dos projetos de reforma da administração como presidente da comissão de reformas administrativas do Comité do Plano ${ }^{28}$, finalmente do artigo 206 da nova constituição venezuelana de $1961^{29}$.

27. O projeto de lei municipal elaborado por uma comissão presidida por SAYAGUÉS LASo, foi enviado pelo Poder Executivo ao Parlamento em 1956, mas vítima da incapacidade típica dos Poderes Legislativos, cujo trabalho não tem sido suficientemente racionalizado imitando por exemplo a constituição alemã de Bonn ou a francesa de 1958 - o Parlamento tem sido impotente - em que pese as mudanças da maioria não só para votar todo texto orgânico, mas ainda para colocá-lo em discussão. O texto do projeto foi publicado pela ."Revista de la Facultad de Derecho y Ciencias Sociales". Montevideu, 1956. A Lei 12.549, chamada orgânica da Universidade, foi mais pràticamente imposta por esta do que pròpriamente votada pelo Parlamento. Cf. nosso artigo La Nouvelle Structure Administrative de l'Université en Uruguay: le cogouvernement des etudiants, "Revue du droit public", Paris, 1963, p. 20-47, reproduzido pela "Revista de Derecho, jurisprudencia y administración", Montevideo, 1962, t. 58, p. 182-201; e pela "Revista de la Facultad de Derecho", Universidad de Carabobo, Valencia (Venezuela), 1962, p. 107-141. A participação de SAYAGuÉs LAso em tôdas as etapas, longas (de 1953 a 1958) e agitadas da discussão universitária do projeto de lei, dá a esta uma unidade técnica muito nítida que há permitido chamá-la, muito justamente, Lei Sayagués Laso. Posteriormente ao Tratado e no relativo à gravitação da dita lei na teoria geral da descentralização, podem ver-se nossos artigos: Entes Autônomos de Enseñanza en el Uruguay, "Revista de administración pública", Madrid, 1963, p. 465-503, reproduzido na "Justicia uruguaya", Montevideo, secção doutrina, 1963, p. 85-115; e La Reforma Universitaria Uruguaya: Autonomía y Descentralización, "Revista del Instituto de Derecho Comparado", Barcelona, 1962, t. XVIII, p. 55-69. Sôbre o mesmo ponto, igualmente, H. Cassinellu MuÑoz, La démocratie décentralisée en Uruguay, "Revue Internationale de Droit Comparé,", Paris, 1964, p. 555-63.

28. La C.I.D.E. (Comissão de inversões e desenvolvimento econômico) criada recentemente no Uruguai para pôr em marcha uma planificação indicativa, considera uma reforma administrativa como indispensável.

29. Indicado expressamente no Preâmbulo da mesma. 
Porém, antes de tudo, Enrigue Sayagués Laso é um espírito extremamente equilibrado, cujo caráter, alimentado por uma fé estóica profundamente vivida, lhe permite enfrentar tôdas as alternativas da existência com uma serenidade socrática: dêste modo não surpreende que tenha conservado uma perfeita lucidez durante os oito dias de sua agonia, e na consciência da proximidade de seu fim, tenha podido alcançar o domínio necessário para continuar preocupando-se com a Conferência de Faculdades de Direito latino-americanas que ia começar poucos dias depois.

Seu equilíbrio excepcional resplandece em seus cursos e funda sua constante vontade de diálogo. Ela o leva a aceitar um convite da Federação Internacional de Juristas Democráticos para concorrer ao Congresso de Pequim, na China Popular, em que pese a campanha desencadeada contra esta viagem pela imprensa conservadora.

Éste equilíbrio se manifesta por um admirável poder yerbal, em que a expressão se adorna de uma sobriedade impecável. Seu talento de expositor se faz notar tanto nas discussões de que participa nos congressos científicos e sociedades especializadas que freqüenta, como nas conferências internacionais, nos conselhos e comités em que sua autoridade lhe reserva um lugar de exceção. Aquêles que tiveram o privilégio de ouvi-lo não esquecerão a qualidade e eficácia de suas intervenções: sabe de entrada e sem rodeios, dar a seu pensamento uma expressão sóbria, concisa, decisiva; as idéias que formula, as soluções que propõe, extraidas de uma ciência profunda e de vasta erudição, sempre são expostas com uma clareza tal que atrai a atenção dos ouvintes.

Deixando-lhes uma estimulante e plena liberdade intelectual, esforça-se em transmitir êste equilibrio às novas gerações. Quer e sabe sempre abrir portas aos jovens, sugerindo-lhes vias novas mas sem privá-los da plena responsabilidade da decisão, que sabe apoiar logo com o pêso de tôda sua autoridade. Professor em sua comarca 
natal, sabe abrir de par a par as janelas do mundo e compartilhar o que sabe. Estimula com entusiasmo, até mesmo com uma paixão que sua máscara de indiferente frieza consegue sem embargo ocultar cuidadosamente, todos os esforços dos jovens juristas latino-americanos desejosos de enriquecer e iluminar no estrangeiro a sólida formação adquirida junto a êle, como alunos ou como assistentes. O caráter excepcional dêste magistério cientúfico se materializa no Tratado de Derecho Administralivo, sua obra capital.

II.

Quando se conhece, por experiência, a quase impossibilidade, para um professor das Faculdades de Direito ibéricas ou latino-americanas, de desprender-se das múltiplas atividades qüotidianas que absorviam sua vida (o Fôro, a Jurisdição, ou a Administração, ou até mesmo duas delas) para consagrar-se quase honoràriamente a uma obra pròpriamente científica, pode-se com mais razão admirar a realização "monumental" 30 do Tratado. Esta obra honraria um jurista europeu que tivesse os maiores ócios. Não se sabe o que mais admirar nela: a abundância e a segurança da informação latino-americana $e$ européia, que supõe longos anos de pesquisas minuciosas e metódicas; o vigor do raciocínio jurídico, que impõe ao leitor cada solução com o rigor da evidência; finalmente, a clareza verdadeiramente límpida da exposição. Muitas vêzes as obras jurídicas impecáveis quanto a uma ou outra destas qualidades, pecam pela ausência de alguma delas. A aliança das três - aliança excepcional em obras de direito - dá ao Tratado valor incomparável.

30. O adjetivo corresponde às crônicas consagradas em duas oportunidades pela "Revue Internationale de Droit Comparé" aos dois primeiros volumes do Tratado. V. t. de 1955, p. 263-65 (por HeNRI Puget e Denis Levy) e t. de 1961, p. 267 (por Denis Levy). 
E obra destinada a tornar-se clássica, uma verdadeira "Suma" do direito administrativo, que será citada durante longo tempo como uma obra magistral. Dela pôde dizer GARRIDo FALla, com sua autoridade expressa na mais alta tribuna da ciência jurídica administrativa contemporânea ${ }^{31}$ :

"Um Tratado de direito administrativo, que, a julgar pela qualidade do primeiro volume publicado está destinado a colocar-se à frente (...) dà produção jurídica administrativa em língua espanhola".

E, José Cretella Júnior, o eminente mestre do direito administrativo brasileiro, assim se expressou:

"O trabalho de EnRique SaYagués LASo, Tratado de derecho administrativo, Montevideo, 1953, vol. I, coloca o Uruguai entre os países em que melhor se sistematizaram as múltiplas questões da matéria. O volume II, publicado em 1959, confirma as qualidades que se observam no primeiro tomo. Obras de amplas perspectivas, profunda, clara, informação bibliográfica de primeira" ${ }^{32}$.

No marco de uma simples rememoração é impossível analisar tôdas as posições adotadas em uma obra que abarca a totalidade do direito administrativo geral. Limitar-nos-emos portanto a examinar, primeiramente o método e a técnica da obra, logo as idéias centrais do autor, cujo desenvolvimento para cada ponto particular se limita à aplicação daquelas segundo as regras de uma lógica rigorosa.

O Tratado, do qual a Revue Internationale de Droit Comparé diz:

31. Revista de Administración Pública, Madrid, 1954, p. 286.

32. Direito Administrativo do Brasil, vol. 1, ed. Revista dos Tribunais, São Paulo, 2.a ed., 1959, p. 187. 
“é pois pela sua importância um verdadeiro Tratado de direito administrativo, como não se publica mais desde o fim do século XIX" ${ }^{33}$,

expõe o Plano da obra em uma introdução concisa e densa, na qual o autor afirma que o direito administrativo é a disciplina jurídica que está exigindo mais urgentemente um ensaio de sistematização. Desenvolvendo-a em tôdas as conseqüências, faz a distinção entre funções e tarefas (cometidos) estatais. As funções, idênticas em todos os estados modernos, são os distintos poderes juridicos que o direito objetivo assinala aos órgãos públicos para que possam atuar e cumprir as tarefas que lhes competem. As tarefas (cometidos) estatais, que variam segundo o grau de intervencionismo ou de socialização de cada país, são as diversas atividades que realizam os órgãos públicos conforme as normas do direito objetivo.

Na América Latina, a influência do direito público e em particular do direito constitucional dos Estados Unidos, tem sido e continua sendo muito considerável: não se deve admirar, pois, que o autor sistematize a função constituinte e eleve a Constituição à categoria de fonte suprema do direito administrativo para os países dotados de uma jurisdição constitucional eficaz. Não é a teoria das funçôes mas a das tarefas estatais que constitui uma originalidade maior: em oposição à doutrina francesa que, prisioneira de uma jurisprudência empírica, faz do serviço público um conceito amplo e excessivamente vago. O Tratado distingue quatro tarefas básicas: as tarefas essenciais ${ }^{34}$, como relações exteriores, defesa nacional e

33. 1955, p. 263.

34. A edição em espanhol do Tratado após distinguir entre funções e tarefas (cometidos) fala das funções essenciais entre as tarefas estatais. O êrro terminológico, indiscutível e criticado por Garrido Falla em seu citado comentário da "Revista de administración pública", é salvado pela tradução francesa. Esta que parece seguir textualmente a primeira edição espanhola, fala de tâches étatiques (cometidos esta- 
segurança, inerentes ao Estado desde o fim do feudalismo, insusceptiveis de concessão, e à respeito das quais os cidadãos têm a qualidade de súditos; os serviços públicos, pertencentes em princípio ao Estado, que pode concedê-los ros particulares mediante o contrato de concessão de serviço público, e diante dos quais os habitantes têm a qualidade de usuários (tais como correios e telecomunicações, energia, transportes); os serviços sociais (tais como o ensino, a saúde pública, a previsão e os seguros sociais), tarefa concurrente do Estado e dos particulares que atuam neste terreno por direito próprio não submetido à concessão mas só à autorização, e a respeito dos quais os habitantes são beneficiários; a ação estatal no domínio da atividade privada (operações bancárias, monopólios fiscais, etc.) mediante a qual, os órgãos públicos, autorizados legalmente entram em concorrência com atividades em princípio reservadas à iniciativa individual, adaptando-se amplamente a uma dinâmica de direito privado.

O sistema das fontes, não tal qual é exposto em poucas páginas no comêço do Tratado, mas tal qual é "rivido" no conjunto dos dois volumes, merece especial atenção. Sente-se nele "o alento enciclopédico da cultura do Rio da Plata" 35: a forte construção teórica do Tratado tem seus fundamentos em um mundo comparativo extremamente rico. É mais e melhor, que o simples direito comparado: a teoria geral, a melhor doutrina da Europa ocidental (francesa e italiana, mas ainda ibérica e alemã), da América Latina, mas também da Inglaterra e da América Saxônica (particularmente quando trata da responsabilidade estatal e do contencioso administrativo), a juris-

tales) entre as quais distingue, em primeiro lugar (p. 12 e 55 ss.) as tâches essentielles. Por isto parece-nos mais adequado ler igualmente em espanhol tarefas essenciais ali onde diz funções essenciais.

35. Segundo a expressão de Couture, Camelutti y nosotros, in Scriti Giuridici in Onore di Francesco Carnelutti, Padova, ed. Cedam, 1950 , t. 1 , p. 319 . 
prudência e o direito positivo dêstes países permanecem na raiz da pesquisa dos critérios de direito positivo, construído dêste modo em tôrno às grandes teorias jurídicoadministrativas, mas que não se encontra sem embargo nunca no nivel de pura teoria. Os juristas europeus têm habitualmente um forte desaprêço pela produção jurídica dos países latino-americanos, que criticam com razão, por desenvolver uma doutrina que nenhum apoio jurisprudencial confirma. O juiz, titular como o legislador de um poder jurídico próprio a êles parece mais próximo da medula do direito que o professor: há nisso, muito particularmente na França e na Alemanha federal, um movimento muito firme que leva os países romano-germânicos à adoção de técnicas da common law. O Tratado não inventa um govêrno dos juízes; mas dá à jurisprudência, fonte do direito, tanto "oriental" como comparado, um lugar de privilégio. Com uma paciência de beneditino, o autor faz um esfôrço de sistematização partindo quase de zero: e o logra. A vida forense e a prática administrativa impregnam sua obra amplamente, é uma espécie de revolução "copérnicana" na técnica do direito administrativo latino-americano ${ }^{36}$.

36. Ainda que a sua forte formação francesa o explique parcialmente, é indubitável que um dos valores jovens mais sólidos e brilhantes da doutrina latino-americana atual, o venezuelano BRWER Carias, deve metodològicamente muito à obra do mestre de Montevideo, convertida em texto da Universidade Central de Caracas. V. os seus recentes trabalhos: Los contratos administrativos en la jurisprudencia administrativa venezuelana, "Revista de la Facultad de derecho", Caracas, 1963, p. 127-154; Las instituciones fundamentales del derecho administrativo y la jurisprudencia venezuelana, tese, Caracas "Publicaciones de la Facultad de derecho", 1964; sua Recopilação dos Pareceres da Consultoria Jurídica do Ministério da Justiça da República da Venezuela sob o título Doctrina administrativa (1959-1963) Caracas 1965; Estudio sobre la delimitación de competencias entre el Poder nacional y el Poder municipal en materia de tránsito y transporte terrestres (con especial referencia a la Municipalidad del Distrito Federal), "Publicaciones de la Governación del Distrito Federal", Caracas, 1965; El régimen jurídico-administrativo de la nacionalidad y 
Mas seu espírito de equilíbrio vela sempre para impedir o excesso contrário. Não é certamente êle que vai impulsionar para um direito administrativo fundado em um impreciso critério existencial. Levado, por uma parte, por êsse gôsto profundo da síntese e essa aptidão particular para aplicá-la que já temos assinalado; intimamente convencido por outro lado, de que "não há ciência a não ser do geral", luta tôda sua vida contra o emprêgo do método empírico e puramente descritivo, opondo-lhe o método vertebral dos princípios jurídicos que Duguit fizera triunfar outrora em França. Desprendendo, não só da doutrina comparada mas fundamentalmente das mesmas soluções de espécie adotadas pela jurisprudência, os princípios de base que as haviam inspirado - e às vêzes mesmo sem conhecimento de seus próprios autores -vincula entre êles êstes princípios de maneira a extrair dêles um corpo de doutrina, susceptivel depois de engendrar novas soluções de espécie. Dêste modo não pode ser acusado de infidelidade do direito positivo, já que seu raciocínio se apoia nele para voltar a êle, tendo no direito positivo sua fonte e desembocadura. Ainda mais, não é difícil a SAyagués LAso demonstrar, pelo contrário, que sòmente êste método permite fundar um direito administrativo estável; tal qual o assinala na Introducción, o esfôrço de sistematização havia-se tornado indispensável para superar o estado caótico das contradições vacilantes de normas e decisões onde os princípios não alcançavam adequada formulação. Sòmente sua decantação pela doutrina permite sua aplicação pela prática e jurisprudência administrativas ulteriores, dando-lhes uma orientação clara que evite sua incertitude ou sua arbitrariedade, tão prejudiciais para administrados e litigantes. Tem a profunda convicção de que sòmente o esfôrço de construção jurí-

ciudadania venezolanas, Caracas, "Publicaciones del Instituto de derecho público", 1965 (em seu Prefácio, o autor dedica sua obra, primeira publicação da coleção do Instituto, em seu próprio nome e em nome do Instituto, à memória do mestre). 
dica de Otto Mayer e Maurice Hauriou havia permitido o progresso do direito administrativo, e que a tendência, seja ao empirismo, seja aos pequenos estudos monográficos, não podia conduzir senão a uma frustração analítica, carente da tensão difícil mas fecunda da síntese. Sua síntese, por outro lado, sua busca da coerência, de um rigor sem falhas, sobrepassa por seu interêsse o campo do direito administrativo: em uma época em que vê o triunfo despótico da burocracia e a desordem anárquica do individualismo, tende à conservação de certos valores humanos fundamentais. E se o Tratado exerce uma profunda influência na jovem geração de juristas latino-americanos, é talvez menos por suas idéias que por seu método, que thes ensina a ver claro em seu pensamento e a ordená-lo de uma maneira harmoniosa.

- 0 direito administrativo alemão e seu principal imitảdor, o direito administrativo italiano, caracterizam-se fruequentemente por construções jurídicas impecáveis, cujo rigor teórico se acompanha às vêzes de um certo desconhecimento das realidades humanas; o direito administrativo francês, pelo contrário, peca, às vêzes, por uma certa falta de lógica, por uma superficialidade teórica que o torna até contraditório e confuso, tal como o prova a jurisprudência sempre vacilante, profundamente empírica, do Conselho de Estado. Porém, neste empirismo dá-se ao mesmo tempo uma busca dos mil matizes da vida, da riqueza inesgotável das situações da administração cotidiana. O direito administrativo ibérico e talvez mais categòricamente ainda o direito administrativo latino-americano, tem buscado sempre a sintese difícil mas apaixonante dêstes dois temperamentos jurídicos. O Tratado logra êste domínio profundo dos princípios, numa linguagem precisa e clara: basta estudar os capítulos sob as noções de órgão, de hierarquia ou de ato administrativo - nos quais consegue dar com uma linguagem diáfana tôda a riqueza de construções juridicas que outros haviam feito incompreen- 
siveis para avaliar mais exatamente seu êxito pedagógico c científico.

Isso se explica também pela rigorosa objetividade. Para quem analisa um sistema de instituições, é grande a tentação de descobrir nele o reflexo de suas próprias doutrinas, mesmo quando não se encontra ali de modo algum: e espíritos excepcionais - Carnelutti, Duguit e talvez o próprio Kelsen - cairam nela. Isso não se poderá dizer de Sayagués Laso. Suas descrições conservam sempre uma imparcialidade rigorosa, que poderia fazer pensar numa certa frieza, aos que não conheceram sua alma apaixonada de lealdade à ciência. Seu Tratado é neste ponto uma obra maestra: esforçando-se por esquecer totalmente sua própria personalidade, realiza nele um esfôrço que exclui tôda simpatia efetiva. Naturalmente que a mesma impassibilidade total se encontra em tôdas suas obras: mas em nenhuma foi mais difícil de alcançar. Não é certamente um mérito menor, haver podido publicar na explosiva América Latina dos anos 1953-64, uma obra que tem sido igualmente apreciada, acima de suas divergências metodológicas e filosóficas, pelos juristas da América Latina e da Europa Ocidental, dos paises da common law e dos países socialistas. A Revue internationale des Sciences Administratives pôde afirmar:

"um notável conjunto comparativo utilizando uma vasta documentação internacional ( ) Nesta matéria, semelhante obra é quase única e honra as ciências administrativas" ${ }^{37}$.

37. Bruxelles, 1960 , p. 310 , que se refere de outra parte a seu comentário anterior, quando do aparecimento do volume I (ibidem, 1956, p. 216-17), onde se dizia: "E indubitável que se os próximos volumes estão à altura de tôdas as promessas e realizações do primeiro, - Tratudo de direito administrativo uruguaio - ou mais exatamente comparado - terá um valor documental e científico de primeira plana" E expressava o voto seguinte, desgraçadamente não cumprido:" (. ) o Tratado compreenderá outros dois volumes, esperados com 
O método comparativo que leva a distinção entre funções e tarefas (cometidos) estatais até suas últimas conseqüências, é posto por SAYAGUÉs LASo ao serviço de uma idéia, a da realização do Sozial Rechtsstaat, do Estado social de direito. Intervencionista moderado, tal qual se depreende de sua mesma classificação das tarefas (cometidos) estatais, reconhece um amplo campo à iniciativa individual na satisfação das necessidades coletivas; mas como é impensável que as ditas necessidades não sejam satisfeitas, tôda tarefa (cometido) estatal pode ser declarada serviço público pela Lei, inclusive os serviços sociais ou as atividades do domínio da atividade privada, dentro dos limites constitucionais. Em potencial, o Estado pode controlar assim por via legal tôda a atividade social ou econômica, já que é inconcebível que os imperativos sociais possam ser contestados por uma concepção caduca das liberdades individuais.

Mas se o Estado é assim social e poderia inclusive ser socialista, é necessário ao mesmo tempo ter uma administração forte e responsável.

o Tratado concebe uma administração forte pelos poderes jurídicos de que dispõe, pelas prerrogativas de poder público contidas no direito que a rege. Escrito antes dos Tratados de Roma - que instituiram o poder regulamentador dos órgãos executivos europeus - e antes da Constituição francesa de 1958, o Tratado não ignora sem embargo as desastrosas conseqüências que tem, para a verdadeira democracia, a aplicação estrita do dogma da separação de poderes, concebido para limitar o poder monárquico e não para freiar a ação de instituições democráticas e republicanas. $\mathrm{O}$ poder executivo necessita um poder regulamentar amplo, e a combinação da noção formal do ato de administração com a noção material do

tanto interêsse com impaciência, já que o conjunto formará incontestàvelmente uma obra que todos aquêles que se interessam pelo direito administrativo devem conhecer e possuir". 
ato legislativo permite ao autor estabelecer os limites materiais da ação legislativa. O Parlamento interpreta a vontade geral, mas o Executivo também; há matérias que escapam à Lei, esta pode ainda ampliar o domínio regulamentar com regulamentos delegados, e os regulamentos de execução podem às vêzes desenvolver amplamente os princípios fundamentais contidos na Lei ${ }^{38}$. Enquanto que a Constituição de Bonn suprimia, sem matizes o domínio da competência regulamentar sàbiamente instituído pela constituição de Weimar, enquanto que a quarta República francesa se debatia na impotência do parlamentarismo, SAYAgués LASo não temia reforçar a teoria de um Executivo forte, indispensável no Estado moderno ${ }^{39}$.

Mas o fortalecimento do Poder Executivo, o limitar a ação paralizante e irresponsável do Parlamento mediante um crescente deslocamento de função legislativa material no seio do Executivo, só é meio de facilitar a ação social do Rechtsstaat". Não constitui, não deve cons-

38. V. em geral, vol. I., p. 120 ss., esp. p. 127-130.

39. A autoridade e o dinamismo do Estado moderno se medem em função da superioridade jurídica (caso da França e da Alemanha federal e, em menor grau, a hoje algo antiquada constituição dos Estados Unidos) ou política (caso dos Executivos britânicos e suíço) do Executivo (eleitoral e jurisdicionalmente responsável) diante do Parlamento. Esta verdade elementar é ainda mais evidente para os regimes políticos carentes de um bipartidismo coerente. Sem embargo, a nova Constituição de 1967, na República Oriental incorre na aberração de afirmar que propugna um retôrno ao "presidencialismo" (quer dizer Executivo unipersonal) quando em verdade instaura um parlamentarismo com Executivo relativamente pluripersonal. SAYAGUÉs LAso não era "colegialista" mas teria certamente criticado com severidade uma reforma constitucional que debilita o Executivo e faz do Presidente um prisioneiro de seus Ministros e em definitivo, de uma classe parlamentária sôbre cuja corrupção e inépcia para enfrentar as exigências do desenvolvimento econômico não há dúvidas. V. REAL, Las estructuras políticas y administrativas uruguayas en relación con el desarrollo, separata da "Justicia uruguaya", Montevideo, 1965, esp. p. 30, ss. Igualmente: GIORGI, La nueva administración pública, Montevideo, Fernández, 1965, p. $35,83,117$. 
tituir um meio de desnaturar o Estado de Direito. O Executivo está também obrigado ao respeito da juridiscidade, noção mais ampla que a simples legalidade e que compreende a Constituição e os princípios gerais do direito. A juridiscidade se aplica a todos os atos de administração, inclusive aos atos regulamentares. Ainda mais: quanto mais forte é um poder, mais severa tem que ser a exigência de responsabilidade: esta se aplica a todos os atos jurídicos (inclusive aos legislativos) e operações materiais. Todo ato jurídico - excetuando os atos de govêrno - é justificável ante o juiz administrativo; e o princípio da devida reparação existe a respeito de todo ato, inclusive com referência aos atos de govêrno ${ }^{40}$.

No sentido da limitação do Estado pelo direito merecem ser destacados dois capítulos, o referente ao contencioso-administrativo e aquêle em que se encontra sua teoria das pessoas públicas. Seu capítulo sôbre o contencioso-administrativo, fruto das meditações do professor, apoiadas numa larga e intensa prática administrativa e forense é uma obra teórico-prática fundamental. Os detalhes mais delicados são expostos por alguém que os tem visto funcionar, os tem manejado, tem contribuído para seu aperfeiçoamento ${ }^{41}$. E são expostos com a preocupação constante de os explicar racionalmente, vinculando-os aos

40. T. II, p. 560 e t. I, p. 404.

41. Com seus precedentes trabalhos sôbre o contencioso-administrativo: El Tribunal de lo contencioso-administrativo, Montevideo, separata da "Revista de la Facultad de Derecho y Ciencias Sociales", 1952, p. 7 ss.; Experiencia y resultados de la creación del Tribunal de lo contencioso-administrativo, Montevideo, "La Justicia uruguaya", 1953; La prueba en los litigios contencioso-administrativos, Montevideo, "Revista de la Facultad de Derecho y Ciencias Sociales" 1954; Los recursos administrativos en nuestro derecho, Montevideo, "La Justicia uruguaya", 1957. E posteriormente ao Tratado, Los recursos administrativos en materia tributaria, Problemas que plantea la creación de la Dirección general impositiva, Montevideo, "Boletín del Instituto uruguayo de derecho tributario", 1961. 
princípios gerais do direito, mostrando as origens e desenvolvimentos contraditórios que se misturam nos direitos estrangeiros. Jurista, êle o é certamente até a ponta dos dedos. Sabe manejar os textos, interpretá-los e desenvolvê-los com ajuda dos mais sutis raciocínios. Mas não se compraz nestes raciocínios por êles mesmos. Não perde nunca de vista as realidades da vida, sempre submetidas à razão ${ }^{42}$.

O capítulo sôbre as pessoas públicas merece ser lembrado em quanto estabelece uma espécie de sistema de freios e contrapesos com um pluralismo hierarquizado, não só de regras (da Constituição até o regulamento) mas ainda de centros personificados de poder com as chamadas entidades estatais menores (entes autônomos, serviços descentralizados, governos departamentais) às que vem anexar-se uma de suas criações mais originais, a das pessoas públicas não estatais, que sistematizando instituições da doutrina italiana, resolve perplexidades e contradições da jurisprudência e doutrina francesas posteriores à decisão Monpeurt, com referência a aplicação do direito

42. A razão o leva a criticar, contra a corrente, o sistema jurisdicional bicéfalo instaurado na República Oriental em 1952, eco irracional do sistema francês. Com efeito, enquanto que a moderna lei espanhola de 1956 e a unanimidade dos países africanos de língua francesa adotam o sistema da única Côrte Suprema - com pluralidade de salas e assembléias plenárias -; enquanto que a maioria dos países latinoamericanos (18 de 21) aderem e com razão ao sistema de unidade de jurisdição, la República Oriental abandona êste, seu sistema tradicional. Esta aberração científica, tendente só a contemplar situações pessoais, não se justifica nem pela especialização dos juízes (igualmente alcançável com salas especializadas do Poder Judiciário) nem pela especificidade, inexistente, do procedimento (t. II, p. 507-08); e tem dado já lugar a casos de denegação de justiça. Cf. Barbe Perez, Um caso de degenación de justicia, comentário das decisões do "Tribunal de lo Contencioso - Administrativo" de 13 de maio de 1953 e da "Suprema Côrte de Justiça" de 27 de agôsto de 1954, Montevideo, "Revista de la Facultad de Derecho y Ciencias Sociales", vol. 5, p. 950 ss. 
público às pessoas de direito privado ${ }^{43}$. São pessoas de direito público, diz o Tratado, mas externas à estrutura orgânica do Estado, o que permite decidir a competência do juiz judiciário, a jurisdição administrativa estando reservada na República Oriental à administração no sentido orgânico. Que na classificação das tarefas estatais teria sido melhor englobar a regulamentação da atividade privada e a justiça entre as tarefas essenciais; que a riqueza das fontes tem talvez o inconveniente de prejudicar a unidade de visão sistemática do direito "oriental"; que não tinha logrado totalmente o estabelecimento de uma doutrina que fôsse não só positiva mas expressões das exigências administrativas dos países subdesenvolvidos; que, em geral, um juridicismo estrito corre o risco de esquecer a ciência administrativa; tais, são algumas reservas de detalhe que poderiam ser assinaladas. Mas nenhuma obra humana é perfeita e esta oferecia dificuldades maiores: o esfôrço era muito novo, os prejuízos a superar estavam fortemente arraigados, para permitir uma execução perfeita por parte de quem se lançava pela primeira vez, qualquer que tivesse sido a fôrça de seu espírito. .

Para a posteridade, o permanente são as novas perspectivas inauguradas pela vida e pela obra de Enrigve SaYagués LAso para a ciência do direito administrativo. Seu método comparativo terá certamente - e muito especialmente nos países da América Latina que têm em Montevidéu o núcleo de sua futura integração econômica e política - uma irradiação em tôda nova teoria geral e em todo esfôrço tendente à unificação do direito ${ }^{44}$.

43. EISENNMANN entreviu uma explicação semelhante: L'arrêt Monpeurt, légende ou réalité? in "L'évolution du droit public (Mélanges en l'honneur d'Achille Mestre)", Paris, Sirey, 1956. Mas a decisão Magnier de 1961 voltou a afirmar uma noção ampla do serviço público.

44. Neste sentido são um modêlo, de futuros desenvolvimentos, suas páginas sôbre o contencioso-administrativo na América Latina, t. II, p. 497-501. 
Contemplando esta vida e esta obra, êste desaparecimento que enluta a ciência do direito administrativo, nos leva a apresentar nossas sentidas condolências a sua espôsa Anita Areco de Sayagués Laso e a seus seis filhos - dois dos quais seguem a rota iluminada por seu pai -; ao mesmo tempo que nosso espírito é levado à meditação do texto seguinte:

"Para quem expõe convenientemente sua vela ao sôpro da Terra, uma corrente se revela que o força a penetrar sempre mais no alto mar. Mais um homem deseja e age nobremente, mais êle se torna ávido de objetivos amplos e sublimes a perseguir. Pronto, a só família, o só país, o só aspecto remunerativo de sua ação não lhe bastam mais. Ele necessitará de organizações gerais a criar, de vias novas a abrir; de causas a sustentar, de verdades a descobrir; um ideal a nutrir e a defender. Assim, imperceptivelmente, o obreiro da Terra não se pertence mais. Pouco a pouco, o grande sôpro do Universo, insinuado, nele pela fissura de uma ação humilde mas fiel, o dilata, o levanta, o arrebata" 45 .

\section{Bibliografia de Henrique Layagués Laso.}

\section{Principais Obras e Trabalhos:}

Suspensión condicional de la ejecución de la pena, Montevideo, Casa A. Barreiro y Ramos, 1932.

Recurso extraordinário de nulidad notoria, Montevideo, premiado no Concurso anual de trabalhos estudantis de 1932, Ed. "Biblioteca de Publicaciones Oficiales de la Facultad de Derecho y Ciencias Sociales", 1934.

El concordato, obra premiada no concurso de obras jurídicas de profissionais de 1934, Montevideo, Ed. "Biblioteca de Publicaciones Oficiales de la Facultad de Derecho y Ciencias Sociales", 1937.

45. Teilhard de Chardin, Le milieu divin, Paris, ed. du Seuil, 1964, p. 65 . 
La licitación pública, tese apresentada para obter o título de Professor adjunto de direito administrativo, Montevideo, Ed. “Biblioteca de Publicaciones Oficiales de la Facultad de Derecho y Ciencias Sociales", 1940.

Estudios sobre contencioso municipal, Montevideo, Atlantida, 1940.

Repertório Jurídico (fndice completo do material legislativo, administrativo, jurisprudencial, doutrinário e bibliográfico, contida em tôdas as revistas ou publicações jurídicas nacionais aparecidas no ano), 4 vols. $(1943,1944,1945,1946 / 47)$, Montevideo, Revista de derecho público e privado.

Tratado de derecho administrativo, Montevideo, vol. I (1953, reeditado em 1959 e 1963), vol. II (1959, reeditado em 1963), ed. do autor. Foi adotado pelas seguintes Faculdades latino-americanas: Montevideo (Uruguay), as duas de Caracas (Venezuela), Medellín (Colômbia), San José (Costa Rica), San Carlos (Guatemala).

Derecho administrativo (2. ${ }^{\circ}$ curso), Montevideo, edição mimeografada pelo "Centro Estudiantes de Derecho" segundo a versão gravada dos cursos dos anos 1956/57, 4 volumes, 1957.

La acción de nulidad ante el Tribunal de lo contencioso administrativo, Montevideo, edição mimeografada pelo "Centro Estudiantes de derecho" segundo a versão gravada do curso especial, 1958.

Traité de droit administratif, Paris, 2 vols., publicado sob os auspícios do "Centre français de droit comparé", prefácio de HENRI PUGET, tradução do Tratado por SIMONE AICARDI (supervisionada pelo autor), 1964 (esta data corresponde de fato ao vol. I, o vol. II tendo sido impresso em 1965 e a distribuição não tendo começado senão em 1966 pela "Librairie générale de droit et de jurisprudence" de Paris.

\section{Artigos em Revistas:}

El principio de las nacionalidades y la protección de las minorías en el derecho internacional actual, Montevideo, "Revista de la Facultad de Derecho" 1932.

Universalidad del juicio sucesorio y alcance de su fuero de atracción, Montevideo, "Revista de Derecho Público y Privado", 1939.

Tribunales de Cuentas, Montevideo, separata da "Revista de Derecho Público y Privado", 1940.

Formas de liquidar las rentas vitalicias al disolver la sociedad conyugal, Montevideo, "Revista de Derecho Público y Privado", 1940.

Procede la acción ordinária contra el Municipio?, Montevideo, "Revista de Derecho Público y Privado", 1941. 
Privilegios y monopolios en las concesiones de servicios públicos, Montevideo "La Justicia Uruguaya", 1943.

Prescripción de la responsabilidad del Estado, Montevideo, "La Justicia. Uruguaya", 1943.

Consideraciones sobre el recurso municipal de lesión de derechos, Montevideo, "La Revista de Derecho, Jurisprudencia y Administración”, 1943.

Criterio de distinción entre personas públicas y privadas, Montevideo, separata da "Revista de Derecho Público y Privado", 1944; reproduzido em Santa Fé na "Revista de Ciencias Jurídicas y Sociales", 1945.

El recurso municipal de lesión de derechos y los actos administrativos complejos, Montevideo, "La Justicia Uruguaya", 1944.

Naturaleza jurídica del Frigorífico nacional, Montevideo, "Revista de Derecho Público y Privado", 1947.

Estudio comparado de la organización y concesión de los servicios públicos en América (incluso aquéllos dirigidos por el Estado, trabalho apresentado na quinta Conferencia de la Inter-american Bar Association em Lima (Peru), Montevideo, "La Justicia Uruguaya", 1948.

Responsabilidad del Estado por acto legislativo (comentário de jurisprudência), Montevideo, "Revista de Derecho Público y Privado", 1948.

La acción de ilegalidad ante los tribunales, Montevideo, "La Justicia Uruguaya", 1949.

Responsabilidad por acto e hecho administrativo, (comentário de jurisprudência), Montevideo, La Revista de Derecho, Jurisprudencia y Administración", 1950.

La responsabilidad por acto o hecho administrativo, Buenos Aires, "Jurisprudencia Argentina", 1950, t. II, secção doutrina, p. 48.

Abogacía libre y abogacía reglamentada (en colaboração com o Presidente do Colégio dos Advogados de Paris Jacques Charpentier, "Jornadas franco-latino-americanas de derecho comparado" (Montevideo, 1948) organizadas pela Faculdade de Direito e Ciencias Sociais do Uruguay e pela "societé de legislation comparée", Montevideo, Ed. "Biblioteca de Publicaciones Oficiales de la Facultad de Derecho y Ciencias Sociales", Montevideo, 1951, p. 1-257.

La condena al pago de intereses y los entes priblicos, Montevideo, "Revista de la Facultad de Derecho y Ciencias Sociales", 1951.

El reglamento, Buenos Aires, "Jurisprudencia argentina", 1951, t. II, p. 68 ss. 
Luego de la ley de derechos civiles de la mujer mantiene la esposa su. derecho a que le sean restituidos los valores enajenados de su dote, o tal derecho ha quedado anulado, total o parcialmente? Montevideo, “La Justicia Uruguaya”, 1951.

Reiteración de las iniciativas del Poder ejecutivo por cambio de titulados de dicho Poder o del Poder legislativo, Montevideo, "Revista de Derecho Público y Privado", 1952.

Responsabilité de l'Etat en raison des actes législatifs, separata do Livre Jubilaire publié pelo Conselho de Estado de França pour conmémorer son cent-cinquentième anniversaire $(4$ nivose an VIII - 24 decembre 1949), Paris, Recueil Sirey, 1952, p. 619, 632.

El Tribunal de to contencioso administrativo, Montevideo, separata da "Revista de la Facultad de Derecho y Ciencias Sociales", 1952.

Naturaleza jurídica del Control de exportaciones e importaciones $y$ del Servicio oficial de difusión radio-elétrica, Montevideo, "La Justicia Uruguaya", 1952.

Naturaleza juridica de los laudos de los Conselhos de salarios y el problema de la retroactividad, Montevideo, "Derecho Laboral", 1953.

Los derechos humanos y las medidas de ejecución, estudo apresentado no Seminário de direito internacional da U.N.E.S.C.O. em agôsto de 1952, em Havana (Cuba); publicado em Montivideo, separata da "Revista de la Facultad de Derecho y Ciencias Sociales", 1953.

El salario y la insuficiencia económica de la empresa para pagarlo, Montevideo, "La Revista de Derecho, Jurisprudencia y Administración”, 1953.

Experiencia y resultados de la creación del Tribunal de lo contencioso administrativo, Montevideo, "La Justicia Uruguaya", 1953.

Responsabilidad por acto legislativo, Lima, "Revista de Jurisprudencia Peruana", 1953, t. II, p. 410 ss.

Disposiciones testamentarias en favor de los testigos de los testamentos cerrados, Montevideo, "La Justicia Uruguaya", 1954.

La prueba en los litigios contencioso-administrativos, Montevideo, "Revista de la Facultad de Derecho y Ciencias Sociales”, 1954.

Concepto de autonomía técnica y su vigencia en el régimen actual de la Facultad de derecho, Montevideo, "Revista de la Facultad de Derecho y Ciencias Sociales", 1955.

Régimen jurídico de los servicios públicos administrados por el Estado, Montevideo, ibidem. 
Les établissements publics économiques en Uruguay, Bruxelas, "Revue internationale des sciences administratives", 1956, separata do tomo 22.

La destitución de funcionarios en los gobiernos departamentales, Montevideo, "Revista de la Facultad de Derecho y Ciencias Sociales", 1956.

Los recursos administrativos en nuestro derecho. Una situación caótica y una posible solución. Proyecto de reglamentación (o de ley.) comentado, Montevideo, "La Justicia Uruguaya", 1957.

Valor y eficacia juridica del acto de adjudicación de la licitación, Montevideo, "Revista de Derecho Público y Privado", 1958.

Los entes autónomos, Montevideo, "Revista del Centro Estudiantes de Derecho", 1958.

La concesión de servicio público, Bolonia, separata dos "Studi in onore di Silvio Lessona", 1958.

Los recursos administrativos en materia tributaria, Montevideo, "Boletín del Instituto Uruguayo de Derecho Tributario”, 1961. 